\title{
Effect of arginine, putrescine and spermidine on the polyamine, proline and chlorophyll content of tobacco (Nicotiana tabacum L.)
}

\author{
Ákos Mendel ${ }^{1 *}$ - László Kovács ${ }^{2}$ - Erzsébet Kiss ${ }^{2}$ \\ ${ }^{1}$ Hungarian University of Agricultural- and Life Sciences, Institute of Horticultural Sciences, \\ ${ }^{2}$ Hungarian University of Agricultural- and Life Sciences, Institute of Genetics and Biotechnology \\ *Correspondence: mendel.akos@uni-mate.hu
}

\begin{abstract}
SUMMARY
Polyamines, such as spermidine (Spd) spermine (Spm) and their direct precursor, the diamine putrescine (Put) are vital and essential aliphatic amines which are also present in plants. Although ethylene and polyamines are also involved in fruit ripening, the genes coding them must also take part in other biosynthetic pathways. In the ethylene and polyamines play an important role in development of salt stress tolerance, and in responses for biotic and abiotic stresses. Exogenous application of all three main polyamines (Put, Spd, Spm) increase salt tolerance of plants, but, accordingly to previous experiments, spermidine has the main effect on the enhancement of salt tolerance. Nicotiana tabacum L. plants were grown in vitro on MS medium, the treatments were as follows: arginine (150 $\left.\mathrm{mg} \mathrm{l}^{-1}\right)$, putrescine $\left(10 \mathrm{mg}^{-1}\right)$, spermidine $(10$ $m g l^{-1}$. Proline, chlorophyll $a, b$ and polyamine contents were measured. The obtained results show that the arginine decarboxylase and the spermidine synthase genes involved in polyamine metabolism, cannot be enhanced by exogenous addition of their precursor molecules. On the contrary, the spermine synthase gene has a positive effect to the lower-class forms of polyamines.
\end{abstract}

Keywords: Nicotiana tabacum L., polyamines, HPLC, arginine decarboxylase, spermidine synthase

\section{Abbreviations:}

ACC - 1-aminocyclopropane-1-carboxylic acid; ADC - arginine decarboxylase; $\mathrm{Ca}$ - chlorophyll $a$; $\mathrm{Cb}$ - chlorophyll b; Ct - total chlorophyll; Spd - spermidine; MS - Murashige and Skoog; ODC - ornithine decarboxylase; PAs - polyamines; Put - putrescine; SAMDC - S-adenosylL-methionine decarboxylase; SAMS - S-adenosyl-L-methionine synthase; SPDS - spermidine synthase; SPMS - spermine synthase.

\section{INTRODUCTION}

Polyamines (PAs), such as spermidine (Spd) spermine (Spm) and their direct precursor, the diamine putrescine (Put) are vital and essential aliphatic amines which are also present in plants (Tun et al., 2006). They can be found in all compartments of the plant, also including the nucleus, which clearly shows their importance in the basic processes of the cells (Bouchereau et al., 1999; Galston et al., 1997; Walden et al. 1997). Polyamine levels are highly dependent upon the plant species, the organ and tissue type, and the developmental stage (Kuznetsov and Shevyakova, 2007). Polyamines are not classified as phytohormones, but similarly to them, they take part in several physiological processes (like growth, senescence, stress response) (Nambeesan et al., 2008).

In Figure 1 we can see, that S-adenosyl-Lmethionine decarboxylase (SAMDC) can be a limiting enzyme in the biosynthesis of Spd and Spm (Mehta et al., 2002; $\mathrm{Hu}$ et al., 2006), while S-adenosyl-Lmethionine synthase (SAMS) can affect the levels of polyamines and ethylene (de Dios et al., 2006). Steps of building up polyamines are made by arginine decarboxylase (ADC), ornithine decarboxylase (ODC), SAM decarboxylase (SAMDC), spermidine synthase (SPDS) and spermine synthase (SPMS) in plants (Martin-Tanguy, 2001).

As we previously mentioned (Mendel et al., 2018), though ethylene and polyamines are also involved in fruit ripening, the participating genes must operate in other biosynthetic pathways too.

Ethylene regulates the growth and development of plants, but in the case of stresses, it behaves as a stress hormone (Abeles et al., 1992). Levels of ethylene and its direct precursor 1-aminocyclopropane-1-carboxylic acid (ACC) become higher to the impact of abiotic stresses (Morgan and Drew, 1997).

In addition to the ethylene, polyamines play an important role in developing salt stress tolerance, and in responses for biotic and abiotic stresses (Kasukabe et al., 2004; Alcázar et al., 2010). Proline and polyamines are the most important nitrogen containing osmolytes in plants (Tarezynski et al., 1993). Polyamines form covalent bonds with macromolecules, such as nucleic acids and (Gill and Tuteja, 2010). Via osmotic regulation, they improve membrane stability, help the removal of free radicals, and influence the actions of stoma in the cases of abiotic stresses (Liu et al., 2007).

Polyamine uptake at the cellular level is a very active and fast process, it reaches the saturation within 1-2 minutes and the cell store them mostly in the vacuoles (Bagni and Pistocchi, 1991).

Spermidine prevents the activation of the superoxide-generating NADPH-oxidase (Shen et al., 2000). 


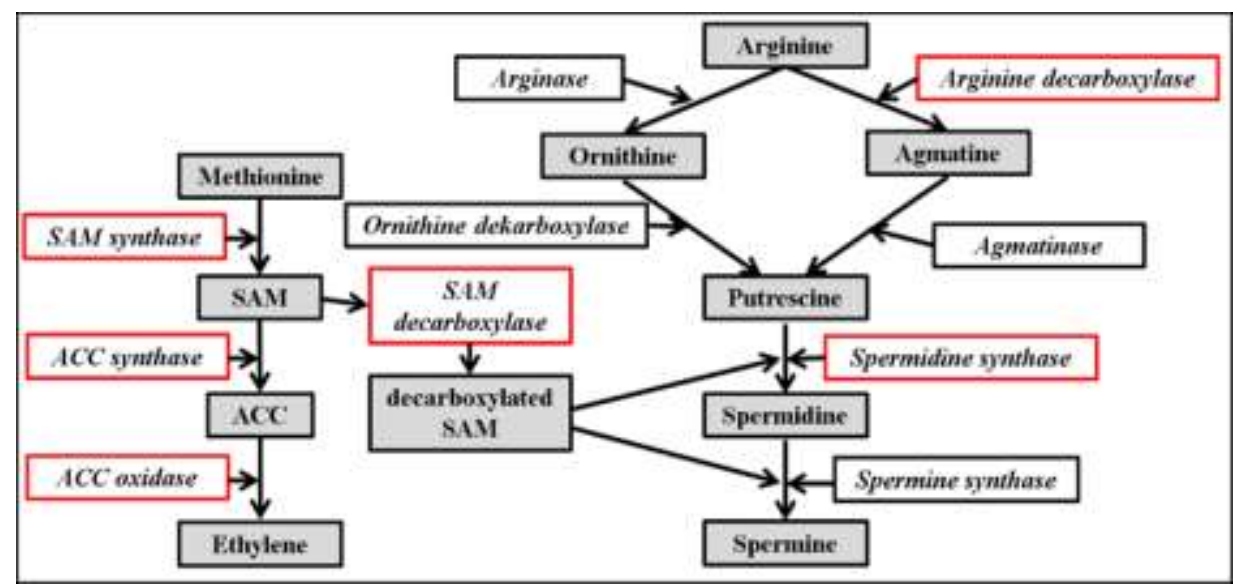

Exogenous polyamines were successfully used to enhance salt tolerance in plants. Exogenous putrescine decreased the accumulation of $\mathrm{Na}^{+}$and $\mathrm{Cl}^{-}$ions in different organs of salt stressed Datura stramonium L. (Ali, 2000). It affected positively the rooting of cucumber seedlings (Cucumis sativus L.) exposed to $100 \mathrm{mM} \mathrm{NaCl}$ stress, as it decreased the $\mathrm{Na}^{+}$uptake and increased the potassium accumulation (Shi et al., 2008).

In addition to the putrescine, exogenous spermidine enhances the salt tolerance of plants through bonding free radicals and maintain the $\mathrm{Na}^{+} / \mathrm{K}^{+}$balance (Saleethong et al., 2011), moreover decreases the $\mathrm{Na}^{+}$ uptake, preventing $\mathrm{K}^{+}$loss (Zhao et al., 2007). According to Zhu et al., (2006) exogenous spermidine blocks $\mathrm{Na}^{+}$transport from the roots to the direction of leaves.

Adding exogenous spermine to salt stressed cucumbers increased the activity of some antioxidant enzymes, such as superoxide-dismutase, peroxidase and ascorbate-peroxidase, which resulted in decreased superoxide anion and malonaldehyde levels (Shu et al., 2013).

Consequently, exogenous application of all three main polyamine forms (Put, Spd, Spm) increased salt tolerance of plants, but accordingly to previous experiments, spermidine has the main effect on the enhancement of salt tolerance.

\section{MATERIALS AND METHODS}

\section{Plant material and treatments}

In our experiment, Nicotiana tabacum L. seeds were germinated in vitro on MS medium in Petridishes. 21 days after germination plantlets were transferred into half strength MS medium with or without the supplements quoted below, three plants in each container. The plants were kept in $16 \mathrm{~h}$ light and 8 $\mathrm{h}$ dark periods at $23{ }^{\circ} \mathrm{C}$. S Treats were as follows: arginine $\left(150 \mathrm{mg} \mathrm{l}^{-1}\right)$, putrescine $\left(10 \mathrm{mg} \mathrm{l}^{-1}\right)$, spermidine $\left(10 \mathrm{mg} \mathrm{l}^{-1}\right)$. Distilled water was used as control. Plants were treated three weeks after germination, samples were collected four weeks later. Samples from three containers per treatments were bulked up, therefore every measurement represents nine plants. Every measurement is performed with these samples.

\section{Chlorophyll $\boldsymbol{a}, \boldsymbol{b}$ content measurements}

Chlorophyll content was determined after the method of Porra et al. (1989). $200 \mathrm{mg}$ of leaf samples were pulverized in liquid nitrogen, then suspended in 2 $\mathrm{ml}$ of $80 \%(\mathrm{v} / \mathrm{v})$ ice-cold acetone. After this, the suspensions were centrifuged at $4{ }^{\circ} \mathrm{C}$ with $12000 \mathrm{~g}$ speed for 20 minutes. The upper phase was recentrifuged for 5 minutes at $4{ }^{\circ} \mathrm{C}$ with $12000 \mathrm{~g} .1 \mathrm{ml}$ $1 \mathrm{M}$ Tris ( $\mathrm{pH} 8.0$ ) was added to $1 \mathrm{ml}$ of supernatant. Chlorophyll $a(\mathrm{Ca}), b(\mathrm{Cb})$, and total chlorophyll $(\mathrm{Ct})$ was measured by NanoDrop ND-1000 UV/Vis spectrophotometer (NanoDrop Technologies, USA) at $645 \mathrm{~nm}$ (Abs.645) and $663 \mathrm{~nm}$ (Abs.663). Contents were calculated by using the following equations:

$$
\begin{aligned}
& \mathrm{Ca}=0.0127 *(\text { Abs.663 })-0.00269 *(\text { Abs.645); } \\
& \mathrm{Cb}=0.0229 *(\text { Abs.645) }-0.00468 *(\text { Abs.663 }) ; \\
& \mathrm{Ct}=\mathrm{Ca}+\mathrm{Cb} .
\end{aligned}
$$

\section{Determination of proline content}

For proline measurement, the following method was used: 2 g leaf was extracted in $3 \%$ sulfosalicylic acid. $2 \mathrm{ml}$ of ninhydrin reagent $(2.5 \%$ ninhydrin dissolved in $60 \%$ glacial acetic acid, and $40 \%$ of $6 \mathrm{M}$ phosphoric acid) and $2 \mathrm{ml}$ of glacial acetic acid was added to $2 \mathrm{ml}$ of aliquot, incubated at $100{ }^{\circ} \mathrm{C}$ for 40 minutes. Then samples were chilled on ice. After this $5 \mathrm{ml}$ of toluene was added, vortexed, and incubated at $23{ }^{\circ} \mathrm{C}$ for 24 hours. The absorbance was measured at $520 \mathrm{~nm}$. L-proline was used as standard (Bates et al., 1973). Proline was determined in the same HPLC examination as polyamines.

\section{Polyamine analysis}

The quantity of free polyamines was determined by the method described by Németh et al. (2002). $200 \mathrm{mg}$ of samples were homogenized in liquid nitrogen, and extracted with $2 \mathrm{ml} 0.2 \mathrm{M}$ ice-cold perchloric-acid $\left(\mathrm{HClO}_{4}\right)$, then chilled on ice for 20 minutes. After this, 
samples were centrifuged at $4{ }^{\circ} \mathrm{C}$ for 20 minutes with $10000 \mathrm{~g}$.

In the case of free polyamine fraction $100 \mu \mathrm{l}$ supernatant was used for preparing dansyl-chloride derivative as Smith and Davies (1985) described:

In a $2 \mathrm{ml}$ Eppendorf tube $200 \mu \mathrm{l}$ saturated sodiumcarbonate and dansyl-chloride $\left(5 \mathrm{mg} \mathrm{ml}^{-1}\right)$ dissolved in $400 \mu \mathrm{l}$ acetone were added to $100 \mu \mathrm{l}$ sample. After homogenization, samples were incubated at $60{ }^{\circ} \mathrm{C}$ for 60 minutes in dark, then $100 \mu$ of proline solution (100 $\mathrm{mg} \mathrm{ml}^{-1}$ ) were added and incubated in dark at room temperature for 30 more minutes. After this, dansylderivatives were extracted with $500 \mu$ of toluene for 30 seconds, and the organic upper phase were transferred to $1.5 \mathrm{ml}$ Eppendorf tubes using a Pasteur-pipette and evaporated in vacuum. Dansylated polyamines were dissolved in $1 \mathrm{ml}$ of $100 \%$ methanol and filtered via tephlone membrane filter $(0.2 \mu \mathrm{m})$. Samples were examined by a WATERS W 2690 (Milford, USA) HPLC device, carrier phase was acetonitrile. Polyamines (putrescine, spermidine and spermine) from Sigma-Aldrich Ltd. were dansylated by the previously described method, and used as standards.

\section{Statistical analysis}

The obtained results were statistically evaluated using the standard deviation and ANOVA methods and these represent the mean values of at least 3 measurements.

\section{RESULTS AND DISCUSSION}

Measured quantities were calculated per gram of fresh weight, summarized in Table 1 .

Table 1. Concentrations of putrescine, spermidine, spermine, proline and chlorophyll $a, b$ in the exogenous arginine, putrescine and spermidine treatments. Data are the means of three replicates $(\mathrm{SD} \pm)$. One asterisk represents significant differences at $\mathrm{P}<0.001$

\begin{tabular}{lccccc}
\hline Treatment & $\begin{array}{c}\text { Putrescine } \\
\left(\mathbf{m g ~ g}^{-1} \mathbf{F w}\right)\end{array}$ & $\begin{array}{c}\text { Spermidine } \\
\left(\mathbf{m g ~ g}^{-1} \mathbf{F w}\right)\end{array}$ & $\begin{array}{c}\text { Spermine } \\
\left(\mathbf{m g ~ g}^{-1} \mathbf{F w}\right)\end{array}$ & $\begin{array}{c}\text { Proline } \\
\left(\mathbf{m g ~ g}^{-1} \mathbf{F w}\right)\end{array}$ & $\begin{array}{c}\text { Chlorophyll } \boldsymbol{a} \text { and } \boldsymbol{b} \\
\left(\mathbf{m g ~ g}^{-1} \mathbf{F w}\right)\end{array}$ \\
\hline Water & 2.98 & 4.77 & 6.81 & 18.09 & 10.48 \\
Arginine & $2, .2^{*}$ & $4.00^{*}$ & $5.81^{*}$ & $16.93^{*}$ & $13.17^{*}$ \\
Putrescine & $2, .2^{*}$ & 4.87 & 6.94 & $17.01^{*}$ & 10.92 \\
Spermidine & $2.37^{*}$ & $2.44^{*}$ & $7.66^{*}$ & $12.70^{*}$ & $11.42^{*}$ \\
\hline
\end{tabular}

It can be seen the graph, that the amount of the polyamines (and their ratio) has appreciably changed only on the effect of spermidine treatment, while at the other treatments the changes are minor. The concentration of proline decreased in all of the three treatments, which can indicate the reduced sensitivity to stress of the plants. This supposed is promoted by the fact, that the concentration of total chlorophyll $a$ and $b$ content increased in these cases.

The Figure 2 shows the measured putrescine, spermidine, spermine, proline and chlorophyll $a, b$ concentrations altered by the treatments in the percentage variance of those in the control plants.

Figure 2. Change of putrescine, spermidine, spermine, proline, chlorophyll and PA content in the percentage of the control

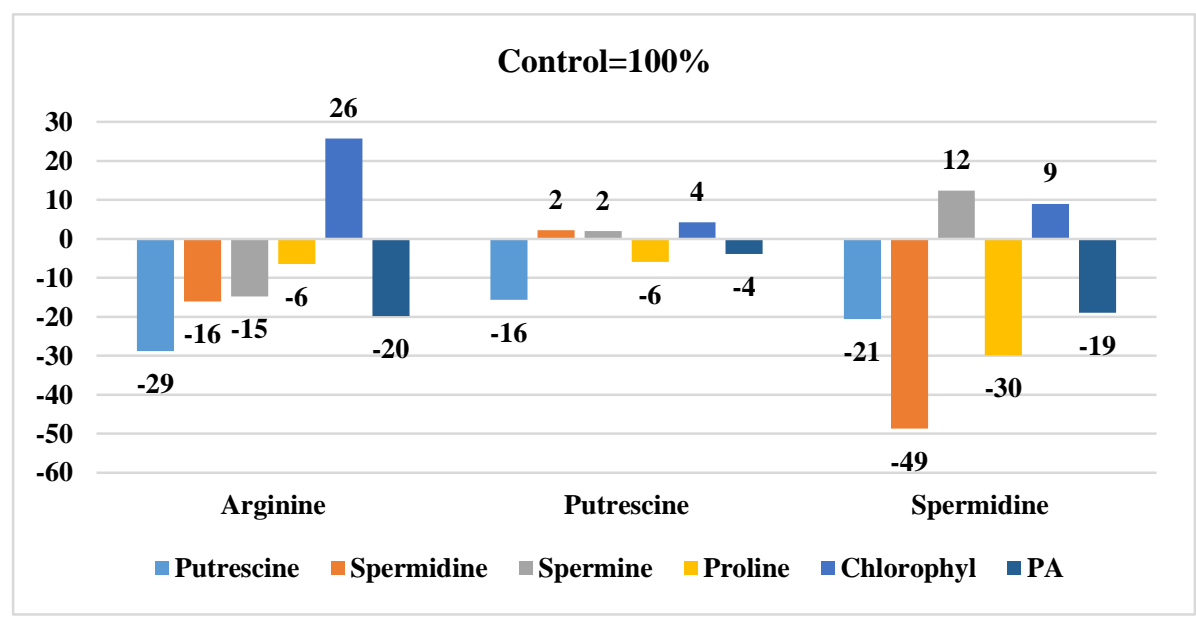

We can see, that the amount of putrescine decreased by $29 \%, 16 \%$ and $21 \%$ on the effect of the exogenous arginine, putrescine and spermidine treatments, respectively. The change of spermidine content is not this obvious at all: decreased by $16 \%$ on the effect of arginine, increased by $2 \%$ in the putrescin treatment, decreased by $49 \%$ while spermidine was added. The amount of spermine decreased in arginine treatment, 
but increased in the effect of putrescine and spermidine treatments (2\% and $12 \%$, respectively). Taken all around, the total content of polyamines (last columns) showed $20 \%, 4 \%$ and $19 \%$ decrease on the effect of the three exogenous compounds. According to PérezAmador et al. (1995), polyamine metabolism in under strict regulation, and is hard to achieve alterations. Minor differences in polyamine-concentrations are available due to catabolic enzymes. Disintegration of polyamines is catalyzed by the copper-containing diamine-oxidase and the flavoprotein-dependent polyamine-oxidase (Kuznetsov and Shevyakova, 2007).

Contrary to these, the concentration of the stress indicating proline showed a 6-6\% decrease to arginine and putrescine addition, and decreased extremely (30\%) to spermidine addition. Accordingly, the amount of chlorophyll $a$ and $b$ content increased by $26 \% 4 \%$ and $9 \%$, which can indicate extended vitality. Presence of polyamines is needed for excessive growth and survival of plants, and for forming a strong abiotic stress tolerance. (Kovács et al., 2020; Kusano et al., 2008).

\section{CONCLUSIONS}

If we compare the measured amounts of putrescine, spermidine, spermine, proline and chlorophyll $a, b$ it turns out, that the exogenous addition of arginine and polyamines also increased the vitality of the tobacco plants, decreased the stress sensitivity without the significant increase of endogenous polyamine levels. Hence, it has lightened that not only the increased amount of polyamines caused the stress tolerance, the effect is also indirect.

The results show that activity of the argininedecarboxylase and the spermidine-synthase genes involved in polyamine metabolism, cannot be enhanced by exogenous addition of their precursor molecules. On the contrary, the spermine-synthase gene has a positive reaction to the lower-class forms of polyamines. For better understanding of mode of action of these genes further investigations are needed.

\section{ACKNOWLEDGEMENTS}

This work was supported by grants from the Hungarian Scientific Research Fund (OTKA 101195) the Research Centre of Excellence - 14764/2016/FEKUT, the ÚNKP-16-2 New National Excellence Program of the Ministry of Human Capacities and the EFOP-3.6.3-VEKOP-16-201700008 project. The research is co-financed by the European Union and the European Social Fund.

\section{COMPLIANCE WITH ETHICAL STANDARDS}

This article does not contain any studies involving animals or human participants as objects of research. The authors declare that they have no conflict of interest.

\section{REFERENCES}

Abeles, F.B.-Morgan, P.W.-Saltveit, M.E. jr. (1992): Ethylene in Plant Biology. San Diego, CA: Academic Press.

Alcázar, R.-Altabella, T.-Marco, F.-Bortolotti, C.-Reymond, M.Koncz, C.-Carrasco, P.-Tiburcio, A.F. (2010): Polyamines: molecules with regulatory functions in plant abiotic stress tolerance. Planta, vol. 231 (6) p. 1237-1249.

Ali, R.M. (2000): Role of putrescine in salt tolerance of Atropa belladonna plant. Plant Science, 152 p. 173-179.

Bagni, N.-Pistocchi, R. (1991): Uptake and transport of polyamine metabolism in plants, In: Slocum R.D., Flores H.E., Eds. Biochemistry and Physiology of Polyamines in Plants: 1991, CRC Press, Boca Raton., 105-118.

Bouchereau, A.-Aziz, A.-Larher, F.-Martin-Tanguy, J. (1999): Polyamines and environmental challenges: recent development, Plant Science, vol. 140 p. 103-125.

Bates, L.S.-Waldren, R.P.-Teare, I.D. (1973): Rapid determination of free proline for water-stress studies. Plant Soil, vol. 39 p. 205207.

de Dios, P.-Matilla, A.J.-Gallardo, M. (2006): Flower fertilization and fruit development prompt changes in free polyamines and ethylene in damson plum (Prunus insititia L.). Journal of Plant Physiology, vol. 163 p. 86-97.

Galston, A.W.-Kaur-Shawhney, R.-Atabella, T.-Tiburcio, A.F. (1997): Plant polyamines in reproductive activity and response to abiotic stress. Acta Botanica, vol. 110 p. 197-207.
Gill, S.S.-Tuteja, N. (2010): Reactive oxygen species and antioxidant machinery in abiotic stress tolerance in crop plants. Plant Physiology and Biochemistry, vol. 48 (12) p. 909-930.

Hu, W.W.-Gong, H.-Pua, E.C. (2006): Modulation of SAMDC expression in Arabidopsis thaliana alters in vitro shoot organogenesis. Physiologia Plantarum, vol. 128 p. 740-750.

Kasukabe, Y.-He, L.-Nada, K.-Misawa, S.-Ihara, I.-Tachibana, S. (2004): Overexpression of spermidin synthase enhances tolerance to multiple environmental stresses and up-regulates the expression of various stress-regulated genes in transgenic Arabidopsis thaliana. Plant Cell Physiology, vol. 45 (6) p. 712 722.

Kovács, L.-Mendel, Á.-Szentgyörgyi, A.-Fekete, S.-Söre, F.-Posta, K.-Kiss, E. (2020): Comparative analysis of overexpressed Fragaria vesca S-adenosyl-L-methionine synthase (FvSAMS) and decarboxylase (FvSAMDC) during salt stress in transgenic Nicotiana benthamiana. Plant Growth Regulation, 91:53-73.

Kusano, T.-Berberich, T.-Tateda, C.-Takahashi, Y. (2008): Polyamines: essential factors for growth and survival. Planta, 228: $367-381$

Kuznetsov, V.V.-Shevyakova, N.I. (2007): Polyamines and stress tolerance of plants. Plant Stress, 1 (1): 50-71.

Liu, J.H.-Kitashiba, H.-Wang, J.-Ban, Y.-Moriguchi, T., (2007): Polyamines and their ability to provide environmental stress tolerance to plants. Plant Biotechnology Journal, vol. 24 p. 117126. 
Pérez-Amador, M.A.-Carbonell, J.-Granel, A. (1995): Expression of arginine decarboxylase is induced during early fruit development and in young tissues of Pisum sativum (L.). Plant Molecular Biology, vol. 28 p. 997-1009.

Martin-Tanguy, J. (2001): Metabolism and function of polyamines in plants: recent development (new approaches). Plant Growth Regulation, vol. 34 p. 135-148.

Mehta, R.A.-Cassol, T.-Li, N.-Ali, N.-Handa, A.K.-Mattoo, A.K (2002): Engineered polyamine accumulation in tomato enhances phytonutrient content, juice quality and vine life. Nature Biotechnology, vol. 20 p. 613-618.

Mendel, Á.-Kovács, L.-Szentgyörgyi, A.-Fekete, S.-Posta, K. and Kiss E., Expression patterns of ethylene and polyamine biosynthetic genes during fruit ripening in strawberry. Studia Universitatis „Vasile Goldiș” Seria Stiintele Vietii, 2018, vol. 28 (4) p. $174-182$

Morgan, P.W.-Drew, M.C. (1997): Ethylene and plant responses to stress. Physiologia Plantarum, vol. 100 p. 620-630.

Nambeesan, S.-Mattoo, A.K.-Handa, A.K. (2008): Polyamines and regulation of ripening and senescence. In postharvest biology and technology of fruits, vegetables, and flowers (Paliyath, G.Murr, D.P.-Handa, A.K.-Lurie, S. eds), USA, Wiley-Blackwell, 319-340.

Németh, M.-Janda, T.-Horváth, E.-Páldi, E.-Szalai, G. (2002): Exogenous salicylic acid increases polyamine content but may decrease drought tolerance in maize. Plant Science, vol. 162 p. 569-574.

Porra, R.J.-Thompson, W.A.-Kriedemann, P.E. (1989): Determination of accurate extinction coefficients and simultaneous equations for assaying chlorophylls $a$ and $b$ extracted with four different solvents: verification of the concentration of chlorophyll standards by atomic absorption spectroscopy. Biochimica et Biophysica Acta, vol. 975 p. 384 394.

Saleethong, P.-Sanitchon, J.-Knog-Ngern, K.-Theerakulpisut, P. (2011): Pretreatment with spermidine reverse inhibitory effects of salt stress in two rice (Oriza sativa L.) cultivars differing in their tolerance. Asian Journal of Plant Science, vol. 10 p. 245254.

Shen, W.-Kazuyoshi, N.-Shoji, T. (2000): Involvement of polyamines in the chilling tolerance of cucumber cultivars. Plant Physiology, vol. 124 (1) p. 431-440.

Shi, K.-Huang, Y.Y.-Xia, X.J.-Zhang, Y.L.-Zhou, Y.H.-Yu, J.Q. (2008): Protective role of putrescine against salt stress is partially related to the improvement of water relation and nutritional imbalance in cucumber. Journal of Plant Nutrition, vol. 31 p. 1820-1831.

Shu, S.-Yuan, L.Y.-Guo, S.R.-Sun, J.-Yuan, Y.H. (2013): Effects of exogenous spermine on chlorophyll fluorescence, antioxidant system and ultrastructure of chloroplasts in Cucumis sativus L. under salt stress. Plant Physiology and Biochemistry, vol. 63 p. 209-216.

Smith, M.A.-Davies, P.J. (1985): Separation and quantitation of polyamines in plant tissue by High Performance Liquid Chromatography of their dansyl derivatives. Plant Physiology, vol. 78 p. 89-91.

Tarezynski, M.C.-Jensen, R.G.-Bohnert H.J. (1993): Stressprotection of transgenic tobacco by production of osmolyte mannitol. Science, vol. 259 p. 508-510.

Tun, N.N.-Begum, T.-Silveira, V.-Handro, W.-Iochevet, E.-Floh, S.-Scherer, G.F.E. (2006): Polyamines induce rapid biosynthesis of nitric oxide (NO) in Arabidopsis thaliana seedlings. Plant Cell Physiology, vol. 47 (3) p. 346-354.

Walden, R.-Cordeiro, A.-Tiburcio, F. (1997): Polyamines: small molecules triggering pathways in plant growth and development. Plant Physiology, vol. 113 p. 1009-1013.

Zhao, F.-Song, C.P.-He, J.-Zhu, H. (2007): Polyamines improve $\mathrm{K}+/ \mathrm{Na}+$ homeostasis in barley seedlings by regulating root ion channel activities. Plant Physiology, vol. 145 p. 1061-1072.

Zhu, H.-Ding, G.H.-Fang, K.-Zhao, F.G.-Qin, P. (2006): New perspective on the mechanism of alleviating salt stress by spermidine in barley seedlings. Plant Growth Regulation, vol. 49 p. 147-156. 
